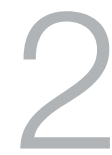

\title{
Pictures for our time and place: Reflections on painting in a digital age
}

\author{
Melinda Hinkson
}

Social theorist Zygmunt Bauman puts forward the proposition that 'life is a work of art'. The statement appears glib without Bauman's further qualification: 'Being an individual', he suggests, '(that is, being responsible for your choice of life, your choice among choices, and the consequences of the choices you chose) is not a matter of choice, but a decree of fate'. Identity, Bauman tells us, needs to be created, just as works of art are created. ${ }^{1}$ In the present we are, he suggests, all artists of life. Bauman's reflections on the art of identity-makingwhich point to certain generalised processes at work in our society more than art creation per se-are confirmed in the observations of other social theorists. Arjun Appadurai argues that with the rise of technological mediation imagination is transformed - it 'has broken out of the special expressive space of art, myth, and ritual and has now become a part of the quotidian mental work of ordinary people'; it 'has become a collective social fact'. ${ }^{2}$ Sociologist John Thompson writes of the defining ontological challenge that confronts us in the present: to coherently integrate two registers in which we experience others 
and the world around us - experience we might simply characterise in terms of presence, and the experience of distance that is enabled by technological mediation, in the first instance by the advent of print and generalised print literacy and then progressively by networked computerisation. ${ }^{3}$

Each of these writers is concerned with the way technological mediation brings about a new social landscape in which the onus is on the individual to draw relations of presence and distance into coherent alignment. This 'new' province of subject formation is the 'old' work of artists. As Hans Belting reminds us, the most basic and complex definition of an image is that it makes an absence present. ${ }^{4}$ Crucially an image cannot execute its own coming into being. Images are made present by the media that make them tangible and animate them and the bodies that produce and respond to them. Belting's model of imagemedia-body transcends the presence/absence binary presupposed by the social theorists while continuing to foreground questions of qualitative distinction between differently mediated forms of image. It is a potent model for thinking about relations between persons and images in the present.

In this essay, I briefly consider these issues from the perspective of two quite different locations. The first is the mediated public sphere. The second is the intimate space of painting production. The link between these locations is painting itself, and, more particularly, attitudes to painting, acts of looking at paintings and making paintings in an era of accelerated technological mediation. Pursuing a nuanced understanding of what might be described as a contemporary cultural attitude to painting, I briefly consider the work of three Canberra-based painters: Micky Allan, Vanessa Barbay and Jude Rae. Significantly, none of these painters is directly engaged with the problem of mediation I have established. All three are committed to painting as a distinctive medium of artistic practice. In looking at their approaches, we nevertheless gain important insights into how technological mediation figures in the cultural practice of painting in the present. We also encounter distinctive

3 John Thompson, The media and modernity: A social theory of the media, California, Stanford University Press, 1995. A large and complex literature tracks the social consequences of technological mediation from print literacy through to the digital period. Among others see Anthony Giddens, Modernity and self-identity, Cambridge, Polity Press, 1991; Walter Ong, Orality and literacy: The technologizing of the world, London, Methuen, 1982.

4 Hans Belting, An anthropology of images: Picture, medium, body, Princeton, Princeton University Press, 2011. 
perspectives on the contemporary problematic of imaging identity in general and portraiture in particular. Before turning to consider this work, I want to explore a minor art scandal that erupted in Australia in 2010 to establish a context for thinking about a contemporary cultural attitude to images. Far from being peripheral to the concerns of a book on portraiture in the digital age, I will argue that in tacking between these spaces of looking at and making artworks, we gain insight into the complex interplay between the life history of persons, place and technological mediation that bear upon contemporary creative approaches to imaging identity.

In April 2010, Melbourne artist Sam Leach took out two of Australia's most prestigious art awards - the Archibald Prize for portraiture and the Wynne Prize for Australian Landscape painting. Public outcry followed the revelation that his entry in the Wynne Prize, the painting Proposal for a Landscaped Cosmos, was 'a copy' of a work by seventeenth-century Dutch painter Adam Pynacker, held in the Rijksmuseum, Amsterdam. On 14 April 2010, the headline on the front page of The Australian screamed 'Double Dutch: Scandal rocks Wynne prize'. Under this headline, the newspaper paired low-resolution images of the two works side-by-side, inviting readers to make their own comparison.
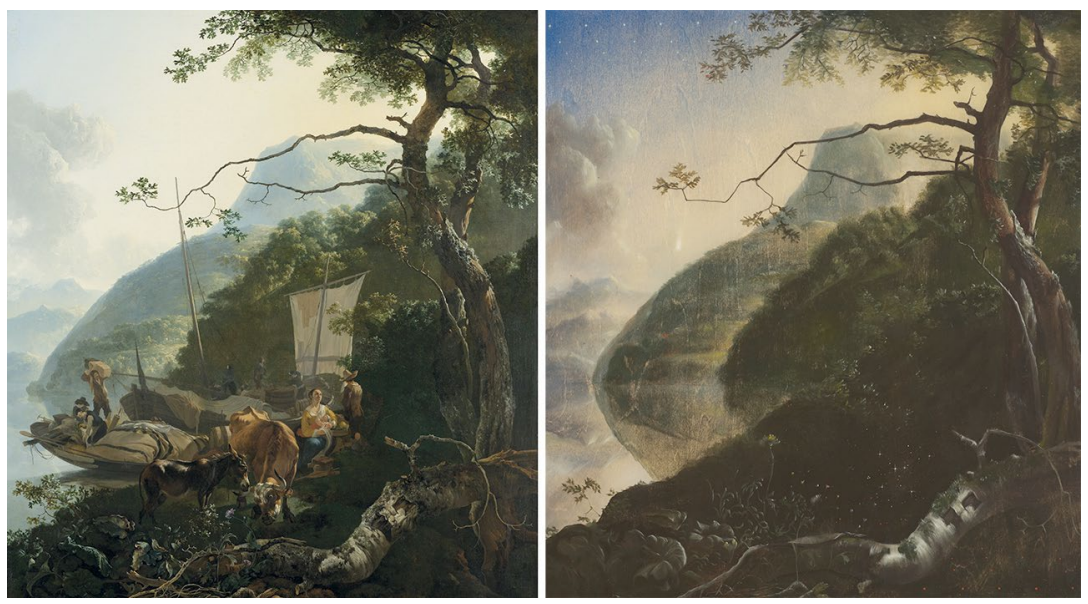

Figure 2.1: Left: Boatmen moored on a lakeshore, Adam Pynacker, 1668; Right: Proposal for landscaped cosmos, Sam Leach, 2010.

Low resolution scans of these two images were reproduced side by side under the headline, 'Double Dutch: Scandal rocks Wynne painting prize', in The Australian and online outlets, 14 April 2010.

Source: Left: Wikimedia commons; Right: courtesy of the artist. 
In the days that followed, Australian talkback radio and the blogosphere were alive with commentary on the 'embarrassing' situation. The Art Gallery of NSW was said to be 'a joke'. The judges' insistence that they would have awarded the prize even if they had known the painting was a 'copy' was said to set off the 'old bullshit meter'. The painting was ridiculed not only as a copy but also a 'poor imitation' that one might 'expect to commission in Asia from the ... workshops that create these sorts of fakes'. And in perhaps the harshest blow to the artist, his 'mediocrity' should have come as no surprise because, as one commentator revealed, Leach was 'merely a graphic designer' ${ }^{5}$

Beyond this online chatter, which might be identified as revealing one dimension of a familiar Australian attitude to art, commentary on the Wynne Prize was interesting for what it seemed to reveal about an attitude to painting, and more specifically landscape painting. Running through the commentary was a desire to see painting conform to particular expectations. Landscape painting should be unmediated: it should deal with what can be seen; it should be about the 'real' environment. Considerable hostility was directed towards Leach for having depicted a Dutch landscape rather than one that was 'authentically' Australian. While the whole episode might easily be dismissed as a predictable clash between a misguided artist who should have properly attributed his painting and persistent modernist desires among 'the public' for a coherent and knowable subject, I want to suggest that the scandal around Sam Leach's painting can be usefully explored in terms of the interests I have established-particularly for what it reveals about a generalised desire in the present for an authentic art (read: painting) that is independent of the effects of technological mediation and its logic of simulation.

Yves-Alain Bois reminds us that such attitudes to painting and the desire for the integrity of specific media are by no means new and by no means restricted to 'the public'. ${ }^{6}$ They emerged in the last quarter of the nineteenth century as part of a general 'attempt to free art from its contamination by the forms of exchange produced

5 All quotes are taken from comments posted on Crikey.com, 14 April 2010.

6 See Diarmuid Costello, 'On the very idea of a "specific" medium: Michael Fried and Stanley Cavell on painting and photography as arts', Critical Inquiry, no. 34, 2008, pp. 274-312. 
by capitalism' ${ }^{7}$ As we approach the present, the urge remains to free art not only from the contaminating effects of the market but from information. Yves-Alain Bois considers the naivety of such longing at a time where 'reproducibility and fetishization have permeated all aspects of life', and indeed have become our " natural" world'. ${ }^{8}$ Given these circumstances, we must shift orientation if we are to identify the substantive work that painting can continue to do. Here Bois invokes Mondrian, for whom painting was,

a theoretical model that provided concepts and invented procedures that dealt with reality: it is not merely an interpretation of the world, but the plastic manifestation of a certain logic that he found at the root of all the phenomena of life. ${ }^{9}$

It is in this deployment of painting as a distinctive method of working through questions, rather than as a means to an end, that we find a compelling response to glib claims of painting's death in the face of photography and the market.

Two weeks after being awarded the Wynne, Sam Leach made his first public comment, appearing on the Australian Broadcasting Corporation's Radio National, in a 30-minute conversation with senior journalist Monica Attard. For the first time the artist made public his intentions in relation to the painting entered into the Wynne prize, telling Attard, 'I wanted to make a painting that was very optimistic, actually, about humanity'. Leach continued:

I wanted to make a painting that was going to be about projecting an idealised landscape into the deep future. That was really the point of it; to say ... maybe humans will actually survive, and maybe if we do ... technology could be used to do something that's quite beautiful.

Here Leach revealed that his painting dealt with a technological theme:

SL: [W] hat I really wanted to do was take that ... idealised, archaic landscape and just flip the meaning from it ... I wanted to take out those things [the figures, the pastoral idyll] the ... golden, idealised past and turn the meaning of the painting into something that's about ... projecting the idea into the future.

7 Yves-Alain Bois, Painting at model, Cambridge, MIT Press, 1993, p. 235.

8 Bois, 1993, p. 242.

9 Bois, 1993, p. 240. 
MA: So then why didn't you just cite the original work?

SL: You know, having said all of that ... the original painting itself is not actually what my work is about. My work is about an idealised future ... when you put a painting into a gallery basically you've only ... got a small amount of information that you can give the viewer and that is the painting itself and the title ... I wanted to make sure my title ... gave viewers a guide to the painting.

MA: With all due respect, I mean, the title is not what you look at. What takes the eye is the image, and the image is strikingly similar to the Pynacker.

SL: [I]t's clear that the painting is based on that original painting. But actually the content and meaning of the painting is quite different from the original painting. And ... if you ... had the original painting and my painting side by side you'd see that there are a number of distinct differences really.

MA: I've seen them reproduced in the media, and to me, what strikes my eye is the jutting landscape ... it almost overrules everything else. So again, I'm surprised to hear you say that, in your mind, that you were creating something distinctly new.

SL: $[Y]$ es, the composition is the same. And I did actually work quite hard to maintain the feel of that original Italianate landscape. If you look at the painting and ... you think that landscape is like the original 17th century, well, that's really part of the intention of the work. But really, when people look at a painting, I think many people at least will look at the detail of the painting and think about how that detail informs the entire work. ${ }^{10}$

This dialogue is revealing for the profound disconnect it registers between painter and journalist, particularly around concepts of representation and authenticity. What I want to highlight is the way each assumes a contrary position regarding the circumstances under which viewers might engage with the paintings in question. The painter makes it clear he assumes a viewer who sympathises with his intentions and, importantly, who will encounter his picture in all its detail in material form, scale, technique and texture. He assumes a viewer with an appreciation for paint, not simply as image, but as material dealt with in particular ways. The journalist expresses

10 Sunday profile, ABC Radio National, Friday 30 April 2010, www.abc.net.au/sundayprofile/ stories/2886663.htm, accessed 1 March 2016, emphasis added. 
a collective desire for an unmediated painting, but simultaneously assumes the viewer's access to these paintings via rescaled digitised images on television or the internet to be unproblematic. ${ }^{11}$ The painter assumes people will be physically in the company of his pictures. The journalist assumes the integrity of mediated engagement. Crucially, while the mediated environment is an essential element of this interchange, it goes unremarked upon by both.

Why do I dwell upon this relatively mundane controversy? It raises questions about how we interact with images in a digital age; questions about what kind of work we wish particular kinds of pictures to do for us in the present; as well as WJT Mitchell's question about what pictures may want from us, ${ }^{12}$ questions about what is at stake in maintaining qualitative distinctions between different kinds of images. In looking to apply an anthropologist's lens to these questions, I move from the abstract space of public debate to some more intimate positions from which to gauge the interactions between persons and images, shifting register to consider how technological mediation figures in the work of three Canberra-based artists, who describe themselves as painters.

I discovered early on in my conversations with painters that the desire for painting to retain some kind of autonomy from the mediated visual cultural environment is by no means restricted to the abstract world of public opinion. Canberra-based painter Micky Allan recalls the Head of the National Gallery of Victoria Art School, John Brack, telling her years after her 1968 graduation that she should have won the finalyear travelling scholarship but that she was ruled out of contention by the judges because she had used a photograph to constitute a subject in her submitted work, rather than painting it direct from life. ${ }^{13}$

As this episode implies, Micky has never harboured a desire to keep painting autonomous from photography. Throughout her career she has moved between and combined several media in her practice. Trained as a painter, painting on canvas is her preferred medium of

11 See interview podcast, Sunday profile, ABC Radio National, 2 May 2010, www.abc.net. $\mathrm{au} / \mathrm{radionational} /$ programs/sundayprofile/sam-leach-wynne-prize-winning-artist/3104550, accessed 4 February 2014.

12 WJT Mitchell, What do pictures want: The lives and loves of images, Chicago, Chicago University Press, 2005.

13 All biographical material and quotations from here on are from interviews with the author, 1 April and 30 April 2010. 
expression, but she has also developed a reputation over the past 30 years for work on etched glass and hand-painted photographs. Micky's biography reflects a common, complex interrelationship between personal experience and creative expression. An early and difficult marriage to another art student saw her painting marginalised in favour of his. By the time the marriage broke down, Micky had stopped painting altogether. Over the next 10 years she lived a highly mobile life, moving between Melbourne, Sydney and Adelaide. While each location gave rise to new artistic projects, canvas painting lay stubbornly dormant.

A move to Sydney in 1978 was precipitated by a personal breakdown. There followed what Micky describes as a 'fabulous period of complete certainty, simplicity, calm'. In Sydney she had her first solo show, which combined drawings, a book of poems and hand-painted photographs, but no paintings. ${ }^{14}$ 'I did photographs', recalled Micky, 'because, why, I wanted to paint, but I couldn't do it. It sort of wouldn't flow.' Micky's hand-painted photographs drew considerable interest, but also hostility, in the heady days of photography's attempts to gain recognition as a distinctive form of fine art. Renowned Australian photographer Max Dupain was observed at one of her shows with tears pouring down his cheeks and was heard to declare, 'it should be stamped out!'

But this painter was neither courting controversy nor attempting to make a critical statement regarding the medium of photography. She was drawn to photography by an altogether more personal set of motivations. For Micky, picking up the camera provided an avenue for venturing out into the world, leaving behind the isolation of the studio. Photography, somewhat paradoxically, brought her face to face with other people. 'I wanted that connection and that engagement', she told me, 'even if it was only there in the second of taking the photo.' There were, of course, also qualities of the photographic image that were particularly appealing - 'the tonal range you can't get in painting; all that fine grain'. 'And there was something about [this] ... this happened, this place exists.' Photography, it seems, as both practice and medium, provided a kind of anchorage, a certainty that Micky needed both socially and artistically. But Micky was repelled

14 Micky Allan, The Live in Show, exhibition at Ewing and George Paton Gallery, Sydney, 1978. 
by the dark room, and especially its chemicals, and was impatient for the photographs 'to be there', ready for her to paint. Photographs were ultimately a form of technical support. Photographs were there in a time when 'painting seemed too hard'.

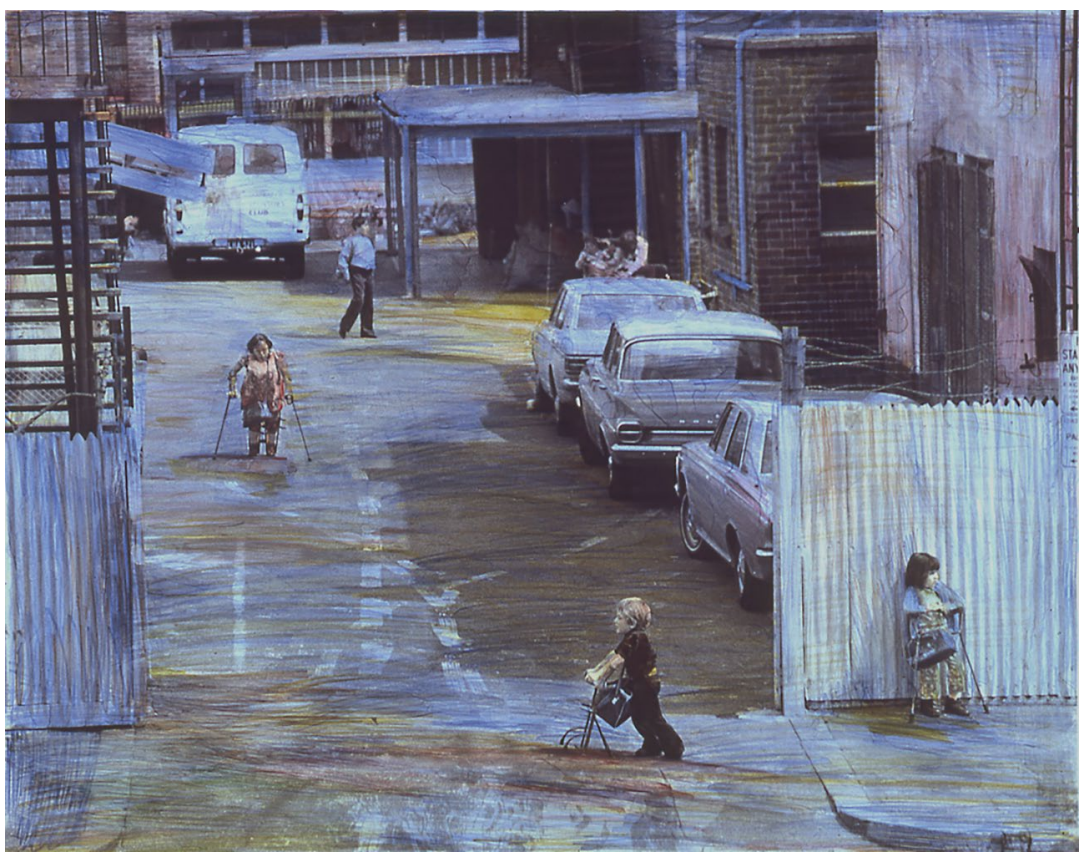

Figure 2.2: Untitled \#2, from the series Yooralla at twenty past three, Micky Allan, 1978, watercolour and coloured pencil on silver gelatin print, $27.7 \times 35.2 \mathrm{~cm}$.

Source: Courtesy of the artist.

Then followed a conscious decision to 'give up the photography', a challenge as difficult, one might surmise from her way of speaking about it, as giving up booze or cigarettes. Going cold turkey, Micky took herself, along with some travelling companions, to the red centre and camped out for an extended period near Uluru, the iconic heart of Australia. Without a tent and living on meagre rations of potatoes for days on end, Micky and her friends wandered around exploring the landscape during the day and then basking in the 'velvet, embracing, expanse of the night sky'. Like a well-disciplined patient withdrawing from her addiction, Micky did not photograph, paint or draw during this time, although she did make some sketches from the window of the moving car. On her return to Adelaide, the creative urge was back and 
Micky produced large charcoal drawings of what she remembered of the desert landforms and 'these imagined strange insects'. She refers to these drawings as some of her favourite pieces. 'They really surprised me, what came out ... They were going into that totally imaginative area that is responding to the place.'

Through the 1990s to the present, Micky has produced series upon series of painted work, wrestling with how to figure in paint the complex interaction of the infinite in the everyday, the interplay between material and immaterial experience, the rhythms of nature, crisis and renewal, and echoes between deep sea, night sky and outer realms of the universe. Mesmerising sweeps of paint are in some works interrupted by a raised fractal, a scatter of glitter, cut coloured-glass marbles, highly textured painted strips. These motifs - often depicting entities beyond tangible reach, such as deep-sea creatures and space matter-are regularly constituted with the help of photography and scanning equipment. The photographic images feed Micky's imagination in ways that are critical to her practice.

The energy and conflicting pulls of Micky's imagination are as evident on the walls of her studio as they are in her manner of speaking. When I visit her one day in April 2010 I am taken aback. In place of the usual riotous scene of colour, materials and works competing for her attention, is an austere calm of empty bench tops and blank white walls. Canvases are stacked away, turned so that their backs face into the room. Materials are filed in draws. The studio has been transformed into a blank canvas awaiting its tenant's next move. As I take a seat a flash of blue catches my eye - a pile of underwater photographs from a recent trip to Cape Leveque in Western Australia lies on a table next to Micky's laptop, tickling her interest.

Jude Rae, who painted Micky's portrait (Figure 2.3), speaks about the studio as lab. ${ }^{15}$ But in her case it might also be characterised as a critical theory workshop. Her paintings are consciously constructed meditations on the nature of contemporary perception. Yet they are emptied of any obvious content that might draw the viewer's attention to such perceptual processes. Jude's still-lifes are of bottles, cheap vases, plastic containers. Her main aim, as she describes it to me, is 'to neutralise the force of association that those sort[s] of

15 Henceforth all quotations are from interviews with the author, 12 April and 23 April 2010. 
objects [still-life objects] carry with them'. She wants to reinvigorate a supposedly exhausted genre via a new set of questions. This process gained further dramatic force with Jude's second series of still-lifes: of fire extinguishers and gas bottles, produced in the wake of 9/11 and the second Gulf War. Her subsequent series of portraits of people with their eyes closed, and then of people engaged in looking at things beyond the reach of the viewer, are similarly a form of genre critique. A particularly striking painting, Self-portrait (the year my husband left), which won the 2008 Portia Geach Memorial Award for portraiture, poses further questions regarding mediation and concealment and the complex encounter of painter and viewer in the work itself.

Jude works with a deep awareness of painting's lack of autonomy; particularly how the forms of vision brought to bear on and through paint today are deeply entwined with the wider visual cultural environment. She wants to produce pictures that get us thinking about how we look at things under these conditions. In order to do so, she needs to withdraw from the 'visual chaos' and into her studio, which she characterises as 'like an extension of my psyche'. Here Jude closes the curtains and immerses herself under fluorescent light in the work of painting, with or without the semi-controlled intrusion of the outside world via Radio National playing in the background.

Some months before our conversations in her studio, Jude was asked to produce a nude for an exhibition being mounted by her New Zealand dealer. ${ }^{16}$ She was eager to be involved but when she came to confront the task encountered a number of hurdles. The first was the genre itself and its historical baggage. As she put it to me: 'How do you make a painting of a nude without a mythological framework?' The second was confronted in the doing. Jude found that she fell back onto the method of the life class, where, to quote her, 'you just plonk a person in front of you and you paint them'. In this case, the person had to be plonked naked in Jude's studio, which was a very challenging experience. The model turned out to be 'too present' to enable the imaginative process to kick in.

16 Naked, on show at Andrew Jensen Gallery, Auckland, 29 April-16 July 2010. 


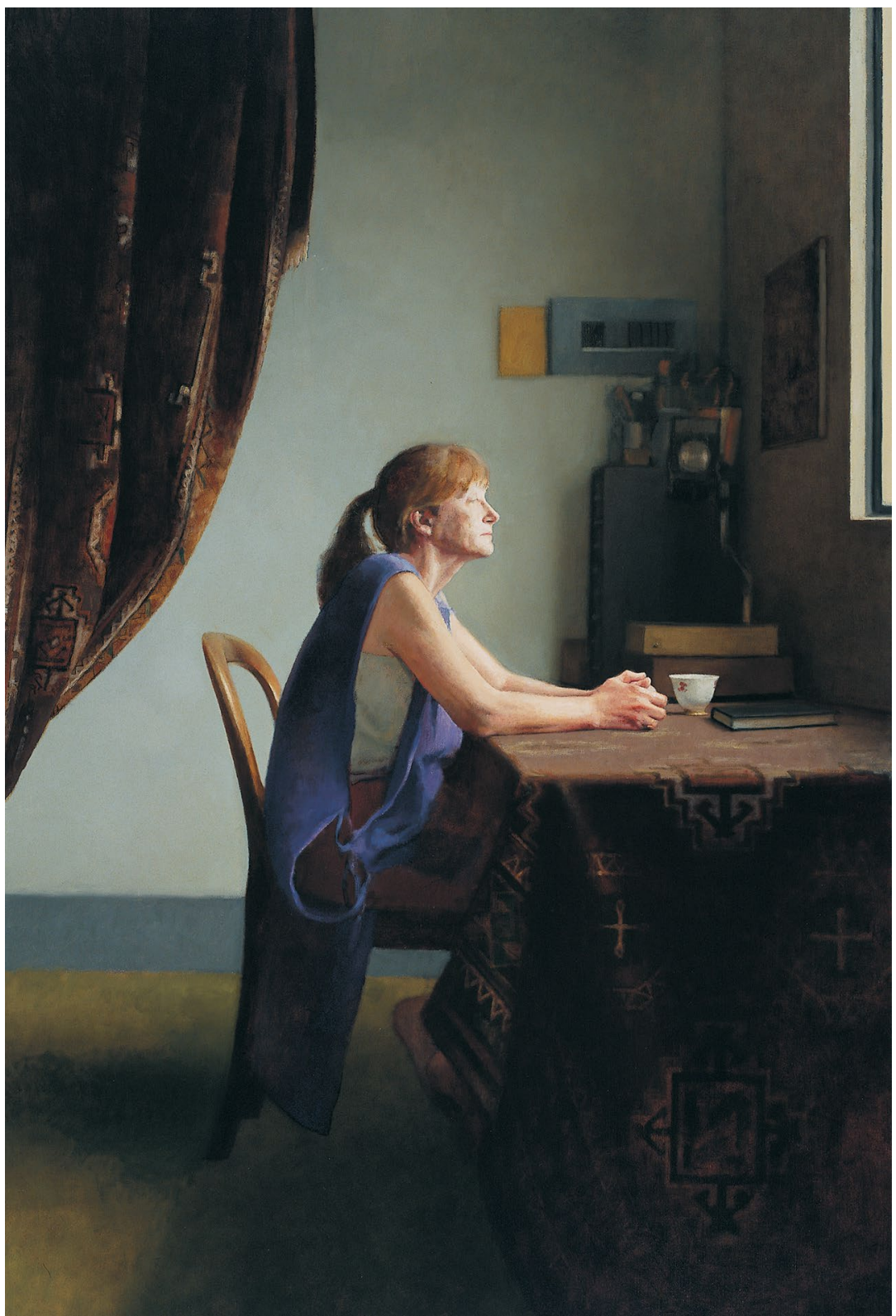

Figure 2.3: Large interior 173 (Micky), Jude Rae, 2005, oil on linen, $180 \times 120 \mathrm{~cm}$, winner of the 2005 Portia Geach Memorial Award for portraiture.

Source: Courtesy of the artist. 
One day, out of frustration, Jude brought her old Canon camera into the studio and set it up to take some video footage of herself while she danced around naked, striking poses to get a sense of the light, trying to work out how she might use a model in that particular space. From this footage she produced a series of blurred, highly pixilated still images. Looking through them Jude saw not pictures of herself but signs that were graspable in terms of art-historical precedent - one particular image stood out, its qualities seemed to reference paintings by Degas, as well as an ancient sculpture of a boy taking a thorn from his foot.

So what had happened in this process? For Jude the camera became a necessary and highly productive distancing mechanism, an objectifying mechanism. As Belting would have it, this doubly digitised process produced a medium for an image, and in so doing enabled the production of a subject - herself - to which she would not otherwise have had access. The photographic process allowed Jude to distance herself from her own body and the problems of the genre, as well as getting 'around the issue of the model in the studio'. In this seemingly simple, stripped-back charcoal drawing on paper is a paradox enabled by the camera.

Jude's drawing (Figure 2.4) is made by a painter who is consciously aware of the effects of the camera on painting - its 'lack of distortion', 'lack of the problems of drawing', its 'hardness and harshness'. While artists like Gerhardt Richter make paintings that comment directly on the visual possibilities and constraints of photography, ${ }^{17}$ Jude's engagement with the medium is more ambivalent. She told me she had a problem with photography intervening in painting 'for a very long time'. 'The guilt that somehow if you use photographs you're somehow cheating the world is still very powerful.' What liberated her was recognising that 'vision is governed by expectation ... When you experience that, it's like, what is the difference between working from a photograph and working from a set of expectations? $?^{\prime 18}$

17 See Peter Osborne, 'Painting negation: Gerhardt Richter's negatives', October, no. 62, 1992, pp. 102-13; also Paul Rabinow, Marking time: On the anthropology of the contemporary, Princeton and Oxford, Princeton University Press, 2008, p. 116.

18 Rabinow, 2008, p. 116. 


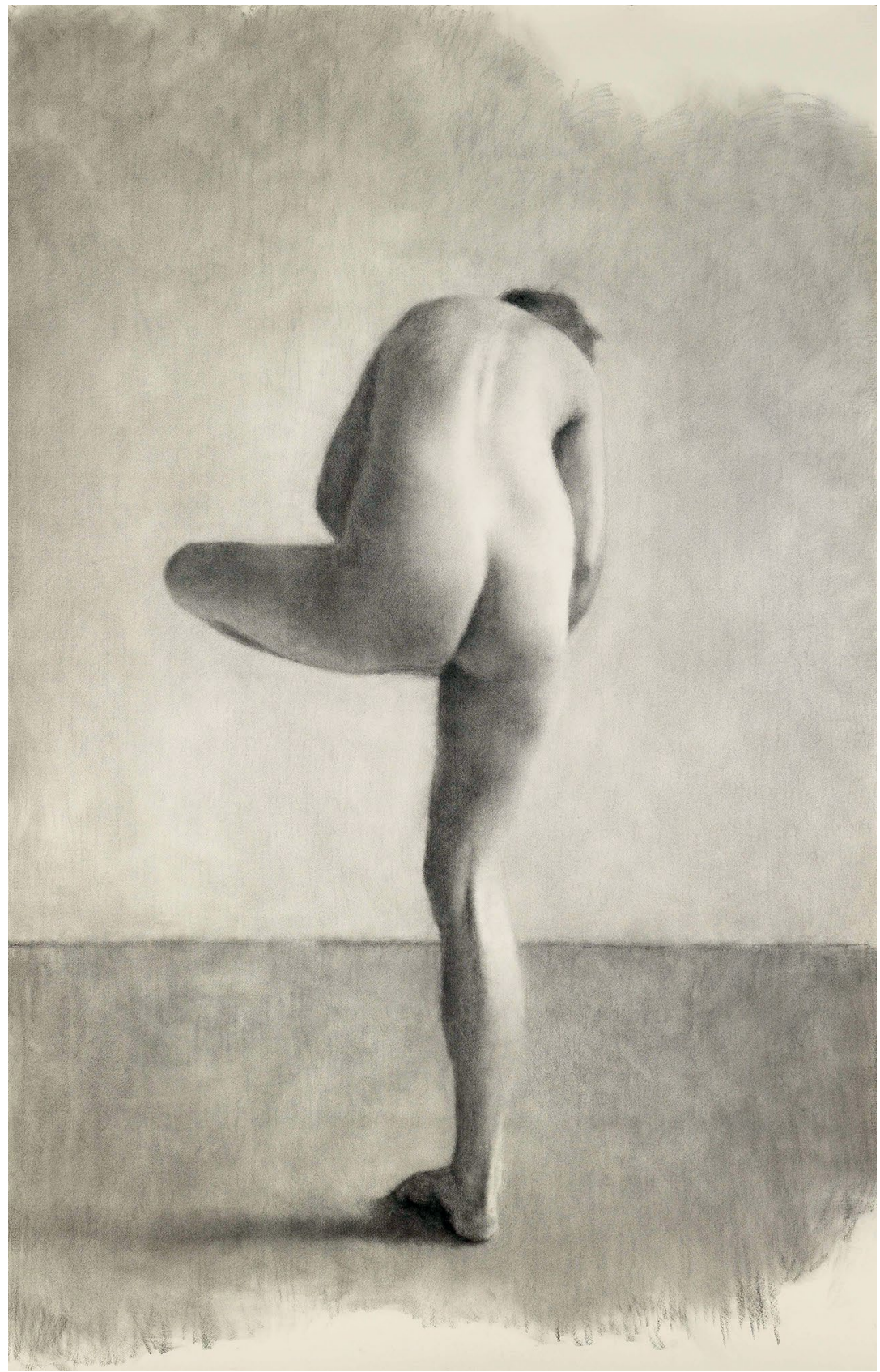

Figure 2.4: Drawing 101 (naked), Jude Rae, 2010, willow charcoal on Fabriano paper, 220 x $140 \mathrm{~cm}$.

Source: Courtesy of the artist. 
In the case of the nude project, the pixilated photograph worked as a trigger for the imagination precisely because it was unlike other photographs, which tend to give 'too much information'. Because a photograph presents an absent subject, Jude reflected, it is 'much less overwhelming in all sorts of ways than having the model in front of you ... It ... creates a space of imagination. It doesn't close it all down ...' 'Working from a photograph', Jude tells me, '... my mind will ... often ... allow me to reflect in a more dreamlike way on my experience of that person. Which is not possible when they are here in front of me. It can take me quite a long way.' So here we are presented with one kind of instance of the beauty of distance. In slightly different ways both Micky and Jude's use of photography seems to share with Gerhardt Richter a desire to counter (or at least temper) the subjectivist tendencies of painting. ${ }^{19}$ Their use of technological mediation is undertaken in support of a thoroughly contemporary culture of painting, not to suggest its end.

A third painter, Vanessa Barbay, confronts the abstract mediation of our time with a poetics of a different register. ${ }^{20}$ Vanessa describes herself as trying to 'discover ways of painting animals that express, or at least incorporate in part, a "regime of involvement" as differentiated from that of scientific detachment'. The regime of involvement invoked is starkly devoid of sentimentality. Indeed, Vanessa seeks to transcend the abstract modes of engagement and representation through which such emotions might be carried. She collapses any clear distinction between representation and the real by incorporating into the pictures themselves pigment and material drawn directly from her subjectsdead animals, road kill-and their environments. From a distance, a painting appears as a mottled swirl of dark and lighter shades of brown, an apparent experiment with colour and materiality. Up close, the surprising essence of the work is revealed: echidna spikes jut out from the canvas at 90 degrees, matted hair and sedimented flesh hold the composition in place. 'Echidna and rabbit-skin glue on canvas', as the materials list for Vanessa's Sorcery painting (autumn echidna) (Figure 2.5) makes clear: the animal is the painting. In this sense, the pictures Vanessa makes are not representations in any conventionally understood sense of the term. These transformational pictures re-enact

19 As observed by Rabinow, 2008, p. 116.

20 This section of the essay draws from Melinda Hinkson, 'Vanessa Barbay: Painting our animal selves', Art Monthly Australia, no. 259, 2013, p. 88. 
and meditate upon something of the human-animal relations that have led to the loss of life of the particular subject with which each work is concerned. Specificity is crucial: place and the materials of particular places loom large in the choices Vanessa makes in the production of each work.

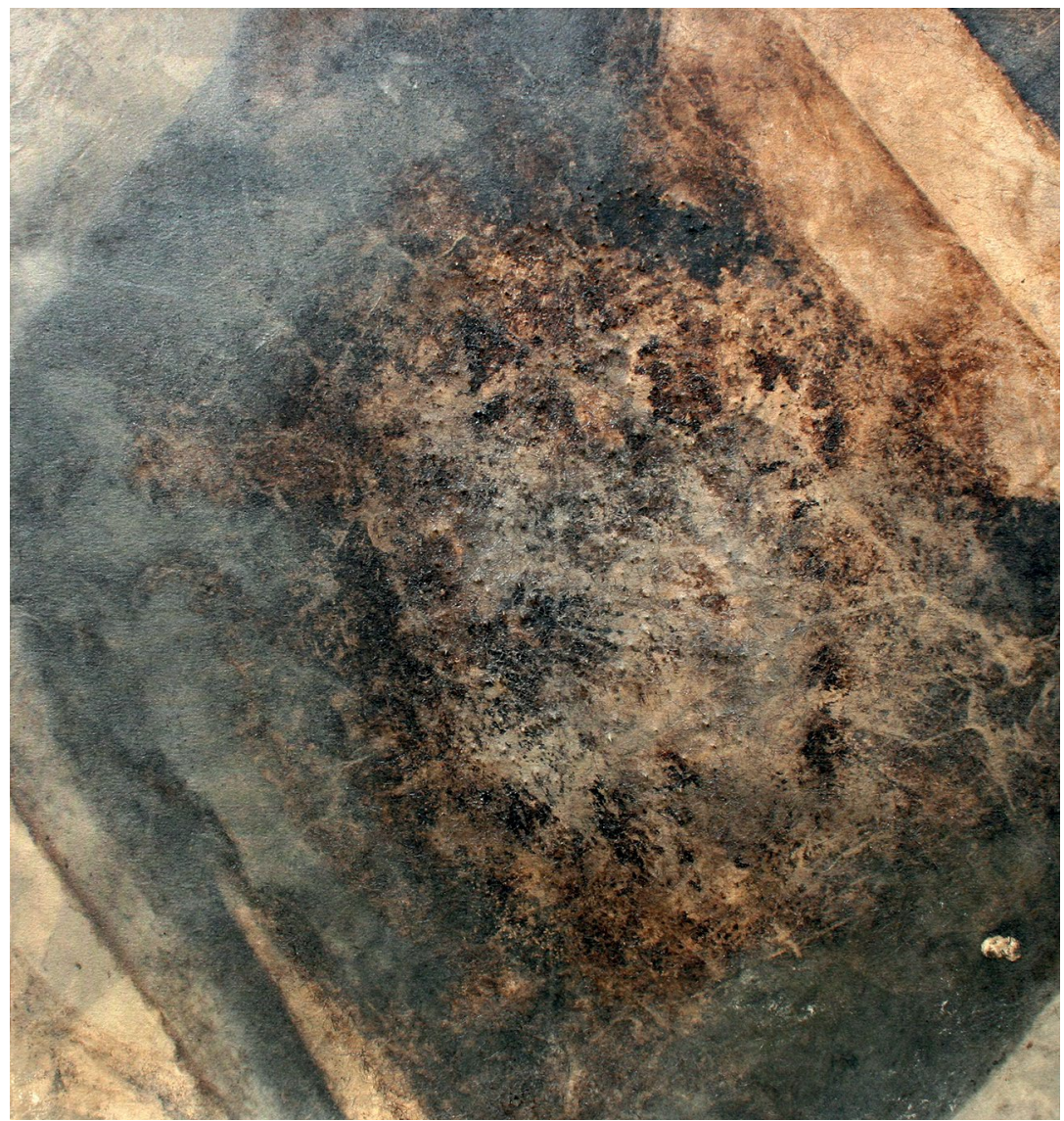

Figure 2.5: Sorcery painting (autumn echidna), Vanessa Barbay, 2011, echidna and rabbit-skin glue on canvas, $84 \times 80 \mathrm{~cm}$.

Source: Courtesy of the artist.

Vanessa describes her method as a kind of mortuary practice, one that enables her to collaborate with the deceased animals, to make works that are redemptive acts, transcending the objectification that lies at the heart of classical painting. Her practice involves a carefully managed decomposition process. Dead creatures are placed on canvas, 
laid out on a sprung bed base and left to the elements beneath a eucalyptus tree on a Monaro property. After a period of months, the canvases acquire shroud-like impressions of bodies, bits of putrefied flesh, as well as eucalyptus sap, dust, rain, marks left by other animals and faint grid-like impressions of the wire mesh protecting the corpses from predators. Most (but not all) shrouds are then domesticated/ deodorised, being steeped in vinegar and infusions of eucalyptus leaves to leach the odour of decomposing flesh.

As Vanessa considers what further creative involvement each shroud asks of her, she gives attention to the particular and local circumstances of each creature's demise. Her choices are also shaped by a wider critical interest in cross-cultural attitudes to the non-human universe, and by an eye attuned to the sacred offerings of nature. Gift (autumn rosella), an ethereal silhouette of a rosella in flight, is the ultimate mystical outcome of the decomposition process, untouched by Vanessa's painting hand except for a coat of rabbit-skin glue. This magical picture has the aura of an ancient religious painting.

Other works are outcomes of the delicate balance between Vanessa's painterly imperative - as the daughter of a taxidermist/collector and two generations of Hungarian artists she has inherited a deeply felt obligation, 'the need to replicate what I see around me' - and her aspiration to transcend that imperative. Where she takes up the paintbrush she does so with a light touch. Wider influences of a childhood closely lived among animals dead and alive, and in association with the Koori community at Vincentia on the NSW South Coast, are evident. Vanessa's more recent research with Kunwinjku painters in Arnhem Land also leaves traces - in the repeated use of delek, spiritually charged white pigment; in restrained experiments with cross-hatching; and in her pervasive attention to the possible sacred outcomes of collaborative engagements between humans, other species and the environment. If Vanessa's artworks are portraits, they demand a reinterpretation of that genre for these works foreground an inextricable set of relationships between the deceased subjects of her paintings, the environment in which those subjects lived and died, and the human attitudes implicated in their demise.

While Vanessa's approach to painting enacts a critique of the abstraction that characterises the dominant contemporary attitude to nature, this does not amount to a rejection of technologised methods. 
Many of Vanessa's works have been created with the intervention of a computer, scanner or projector. The projected outline of a bird's nest and dead bird are traced with gesso onto canvas prepared with nothing but rabbit-skin glue. The completed work enfolds the projected image as a component of its making, but, like Jude's nude, does not reveal its crucial involvement to the viewer.

To some extent these technical supports are drawn into the process of making paintings under the pressure of the institutional environment in which they are made - the university-based art school. ${ }^{21}$ Vanessa's strong moral preference to paint directly from life (or death) is qualified by her concern to meet the requirements of her $\mathrm{PhD}$ program, to reveal the processes of making to her examiners, and to meet the 'milestones' and projected outcomes of annual plans. In this respect, her carefully crafted regime of involvement with her subjects and her practice are challenged by the institutional requirement to make paintings more quickly than might otherwise be the case. Projecting images of dark and light onto the canvas so that they might be traced out with efficiency is one kind of compromise made by painters in the art school setting, alongside other constraints related to the cost, and therefore choice of materials, size of canvases and number of paintings made.

To link the consideration of these painters' work back to the issues with which I began, in describing our vision of the world as 'bifocal', anthropologist John Durham Peters suggests that one of the great ironies of contemporary experience is that the distant, or the global, which we grasp through media images,

becomes clear through representation, whereas the immediate is subject to the fragmenting effects of our limited experience. Our sense organs, having evolved over the ages to capture immediate experience of the local, find themselves cheated of their prey. ${ }^{22}$

21 See the contributions to Brad Buckley and John Conomos, Rethinking the contemporary art school, Nova Scotia, The Press of Nova Scotia College of Arts and Design, 2009, for an examination of the range of issues and pressures brought to bear on university-based art schools in the present. 22 John Durham Peters, 'Seeing bifocally: Media, place, culture', in Akhil Gupta and James Ferguson (eds), Culture, power, place: Explorations in critical anthropology, Durham and London, Duke, 1997, p. 79. 
John Durham Peters seems here to capture something of Jude Rae's experience of being overwhelmed by the presence of the naked model in her studio. We may well observe that studio-based nude life-painting was a common mode of painterly practice of an earlier period. In the digital era, the physically present model may no longer be a familiar or regular element in painterly practice, as painters take inspiration from all manner of objects and phenomena, mediated in all manner of ways. In what Mitchell describes as the latest biocybernetic turn in our relationship with images, the image-worlds created in our time enact the increasingly central and intimate place of technologies in a distinctive way of being human. ${ }^{23}$ The subjectivity of persons who identify as painters is as much caught up in these transformations as is the case for the rest of us.

Yet, as a number of writers have observed, paintings continue to demand a different register and temporality of engagement from the fleeting, screen-based images that currently dominate daily experience. TJ Clark and Didier Maleuvre argue that, increasingly, we take the attitude that characterises our interactions with fleeting commodified images into our engagements with other kinds of images, including paintings. ${ }^{24}$ This is the logical consequence of late capitalism, which has called out not only a distinctive form of image but, along with it, a distinctive cultural attitude through which persons interact with those images.

It is unsurprising that under these circumstances there may be a strong social demand for painting to stand for what is thought to be natural, or unmediated. While the painting practices considered here demonstrate that painting in the present is technologically mediated activity, these artists continue to privilege what they understand as a logic of painting; that is, a method of working-through, a method that only at its conclusion gives rise to 'production'. What is strikingly the case across the work of these three painters is that none wish painting to be free of the possible effects of technological mediation. Their enterprise presupposes a flow across art forms and ways of seeing: the possibility of troubling, and indeed undermining, binary

23 Mitchell, 2005.

24 TJ Clark, The sight of death, New Haven and London, Yale University Press, 2006; Didier Maleuvre, 'A plea for silence: Putting art back into the art museum', in Hugh Genoways (ed.), Museum philosophy for the twenty-first century, Lanham, MD, Alta Mira Press, 2006. 
distinctions such as those between presence and distance, immediacy and abstraction, materiality and intangibility. Given this, there is a kind of double movement in their works - on the one hand, a drawing of attention to thoroughly contemporary phenomena, on the other, a casting of their concerns in more transcendental, universal terms.

In this way, painting practice might be grasped as a form of mythmaking. During my discussions with painters I have been regularly reminded of anthropologist Claude Levi-Strauss' work on myth, which he describes in terms of a universal human need to enact in narrative form the contradictions with which we live. ${ }^{25}$ Within the structures of myth, Levi-Strauss identifies elements directed at overcoming those contradictions. Art, he suggests, lies midway between science and myth. Artists construct objects from a limited set of materials and tools, but the objects produced are simultaneously objects of knowledge. Artworks have a special ambiguity in that they are both closed and open forms. ${ }^{26}$ This kind of interpretation is particularly helpful for thinking about the distinctive place of painting in our digitally dominated contemporary world; painting is both of the times and contrary to it. Painting may be observed to stand outside of and be opposed to the digital yet, as we have seen, its practice often unfolds in intimate engagement with digital technologies, in much the same ways that painters work within and against the temporal structures and ways of seeing associated with the digital visual culture environment they inhabit. ${ }^{27}$ Contemporary painting carries its charge in how it holds this apparent paradox in productive tension. As a medium of the present, painting cannot simply be described in terms of the materials that render its finished form.

The works of these three painters indicate a dilemma that returns us to the Sam Leach case. Viewers of Jude Rae's nude or Vanessa Barbay's animal shrouds or Micky Allan's underwater worlds have no access to the stories and techniques of how these pictures were created. And unlike Leach's painting, their titles give nothing away. Thus I conclude by posing several questions. Does it matter that a charcoal

25 Claude Levi-Strauss, Structural anthropology, volume 1, Harmondsworth, Penguin Books, 1977.

26 Claude Levi-Strauss, 'The science of the concrete', The savage mind, Chicago, Chicago University Press, 1966.

27 See Melinda Hinkson, 'Australia's Bill Henson scandal: Notes on the new cultural attitude to images', Visual Studies, vol. 24, no. 3, pp. 202-13. 
drawing would not exist but for a technologically mediated process of creation? What difference does it make that a painting is composed of the very materiality of its subject? The answer returns the weight of responsibility to the viewer. Just like the journalist interviewing Sam Leach, the viewer of these paintings may not hear or see the message the artist is attempting to convey. It is only when we slow down to look ${ }^{28}$ and allow pictures to work on us that they establish themselves as images that speak to us and to our contemporary visual culture environment. In Jude Rae's work, we have a nude that refuses to give up its face and front the gaze of the viewer, a nude that refuses to present itself in the visual language that most commonly addresses the late-capitalist consumer. The work of each of the three painters considered here refuses to conform to conventional expectations of what painting is for. Or are these simply beautiful pictures? You be the judge.

\section{Acknowledgements}

Ethnographic research with Micky Allan, Vanessa Barbay and Jude Rae was conducted in 2010. I am most grateful to each of these artists for welcoming me into their studios and for their openness and critical engagement in reflecting upon what it means to be a painter in the digital age. 
This text is taken from Imaging Identity: Media, memory and portraiture in the digital age, edited by Melinda Hinkson, published 2016 by ANU Press, The Australian National University, Canberra, Australia. 